doi:10.17659/01.2021.0035

Journal of Case Reports 2021;11(2):131-134

\title{
Altitudinal Variation in Prevalence of COVID-19 Infection in India: Data-based Analysis
}

\author{
Shazia Durdana \\ Department of General Medicine, Jawaharlal Nehru Medical College, Aligarh Muslim University, Uttar Pradesh, India.
}

\section{Corresponding Author: \\ Dr Shazia Durdana \\ Email: durdana786.sd@gmail.com}

This is an Open Access article distributed under the terms of the Creative Commons Attribution License (creativecommons.org/ licenses/by/3.0).

Received Accepted Published

March 15, 2021

June 12, 2021

June 25, 2021

\begin{abstract}
Background: The present study aims to analyze the epidemiological data of COVID-19 in Indian subcontinent in terms of altitude, to understand the difference in body's response to COVID at high altitudes in comparison to low-lands and to understand whether physiological adaptation to counteract hypoxic environment at high altitudes, is also protective against adverse impacts of COVID-19. Material and Methods: The relationship of the reported positive cases and COVID deaths per million population was compared at different altitudes. Results: COVID-19 positive cases decline with high altitude. Conclusion: There might be a positive role of high altitudes in decreasing the prevalence of COVID-19 infection. Various environmental and physiological factors that might contribute to the altitudinal variations in COVID-19 are also discussed.
\end{abstract}

Keywords: Acclimatization; Altitude; COVID-19, Hypoxia, Erythropoietin.

\section{Introduction}

SARS-CoV-2, engendered a global pandemic, rapidly spreading to more than 120 countries as a major threat to public health $[1,2]$. WHO COVID-19 situation report dated September 22, 2020, suggested 31,179,392 confirmed cases worldwide including 962,649 deaths [3] and 5,562,663 confirmed cases with 88,935 deaths from India [4]. European data demonstrated reduced incidence of COVID-19 at higher altitudes [5,6] suggesting positive influential role of physiological adaptation at high altitudes in decreasing susceptibility to SARS-CoV2. However, data regarding altitudinal variation of SARS-CoV2 infection in Indian subcontinent is sparse. This study aims to analyze the COVID-19 epidemiological data in India and its physiological implications.

\section{Materials and Methods}

The COVID-19 database of the open data website of Ministry of Health and Family Welfare, Government of India (https:/www.mohfw.gov.in/) obtained on September 22, 2020 was analyzed to study total number of confirmed COVID-19 cases as well as deaths attributed to COVID-19 in various states of India. Data of population of Indian states was obtained from Census of India 2011 website (http://censusindia.gov.in/2011-prov-results/ paper2/data_files/india/paper2_1.pdf). Distinct linear models were explored to assess the relation of the reported positive cases and COVID deaths per million population, with altitudes.

\section{Results}

It was observed that, the number of cases positive for COVID-19 appeared to decrease with altitude of residence. Furthermore, number of deaths were also significantly lower as altitude of residence increased. These effects are particularly relevant at altitudes of 2000-3000 metres or more above sea level as shown in Fig.1. These findings resemble with the study conducted by Christian Arias-Reyes et al. [6], who analyzed the epidemiological data of COVID-19 of Tibet and high-altitude regions 
of Bolivia and Ecuador, and compared to lowland data, and concluded that there is a decreased prevalence of SARS-CoV2 infection in people living at high altitudes.

\section{Discussion}

This epidemiological data suggests decreased prevalence of SARS-CoV2 infection as well as lesser number of deaths due to COVID-19 at higher altitudes as compared to low altitude areas of India, thus indicating a positive influential role of high-altitude physiological adaptation to hypoxia in prevention against SARS-CoV2 infection. It is well-established now that SARS-CoV2 infects the host cells via angiotensin converting enzyme 2 (ACE2) receptors [7] that are found in abundance in cells lining the respiratory tract, lung alveolar epithelial cells, heart, arteries, veins, kidney and intestines [8]. ACE2 receptors play a central role in pathogenesis of SARS-CoV2 infection as shown by various prior studies. Emerging data have presented the concept of RAS (renin-angiotensin system) acting as dual-axis system with traditional axis represented by ACE-1 (angiotensin converting enzyme type 1) acting mainly as vasoconstrictor, and a new axis represented by ACE-2 (angiotensin converting enzyme type 2) which is vasodepressor [9]. Under normal circumstances, RAS system is regulated by the dynamic equilibrium between the expression of ACE1 and ACE2. However, in response to chronic hypoxia, this balance between ACE1 and ACE2 is disturbed and there is upregulation of ACE1 while the expression of ACE2 is markedly decreased in human pulmonary artery smooth muscle cells (hPASMC) [10]. A previous animal study supports this working hypothesis by showing that ACE2 knock-out mice develop significantly less acute lung injury after infection with SARS-CoV2 [11]. Similar results were demonstrated in a study conducted by Dang et al. who demonstrated increased levels of ACE1 and decreased expression of ACE2 in heart cells of rats exposed to hypoxic condition equivalent to the one found at high altitudes [12]. Thus, these

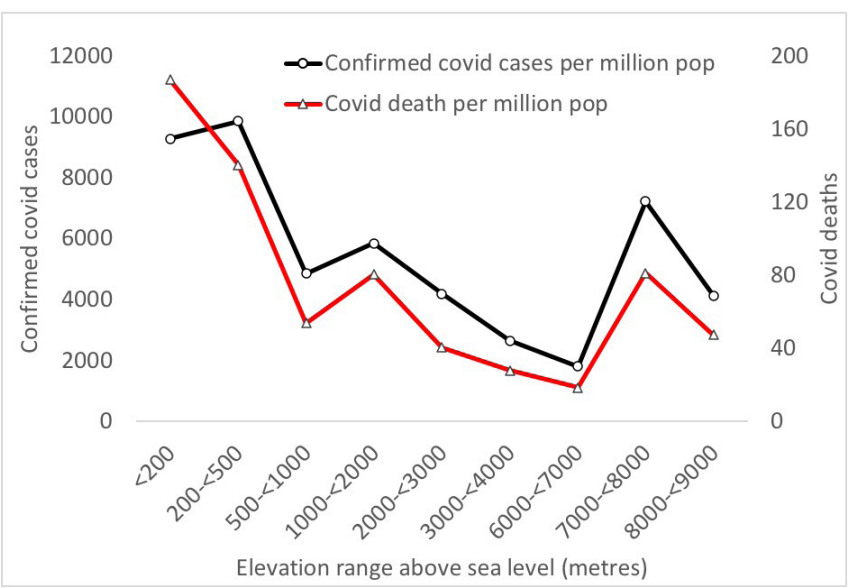

Fig.1: The trends in number of confirmed COVID cases and number of deaths attributable to COVID-19 (per million population) and their relation with elevation above sea level.

findings of decreased level of ACE2 expression in response to chronic hypoxia, that usually occurs at high altitudes, is quite promising in explaining the decreased prevalence of SARS-CoV2 infection at higher altitudes and successful physiological adaptation to high-altitude environment could render local inhabitants relatively less susceptible to SARS-CoV-2 virus penetration and subsequently are protected from the development of severe COVID-19 infection.

Furthermore, these epidemiological findings of decreased SARS-CoV2 infection rate among high altitude inhabitants also raises the question of whether physiological mechanisms underlying the acclimatization to high altitude identify therapeutic targets for the effective treatment of COVID-19, which could account for decrease in mortality rates associated with SARSCoV2 infection. Acclimatization to high altitudes with hypoxia involves immediate and gradual physiological adjustments of the respiratory system [13]. Immediate response to emerging hypoxia involves carotid body-mediated compensatory hyperventilation [14] whereas sustained hypoxia induces the increased secretion of erythropoietin (EPO) from liver and kidney cells which results in a gradual increase of red blood cells over a period 
of two weeks (or longer, depending on the altitude) and stimulates oxygen uptake and transport [15]. Thus, EPO serves as a major regulator of physiological acclimatization at higher altitudes and keeping in view, the positive influential role of high-altitude acclimatization, EPO can be thought of as an adjuvant treatment for COVID-19 induced hypoxia [16], although this requires further studies. Besides physiological adaptation, certain environmental factors may also contribute to decreased prevalence and severity of SARS-Cov2 infection among high altitude inhabitants.

High-altitude environment has higher ultraviolet (UV) radiation that may play a major role in decreasing the virulence of SARS-CoV2. Studies suggest that in relation to SARS-CoV-2, UV-A and UV-B radiations cannot achieve complete disinfection, but they may shorten the half-life of any given virus by causing alterations in molecular bonds of the DNA and RNA, thus reducing the survival capacity of the virus at higher altitudes [17]. Furthermore, another benefit of greater UV radiation at high altitude might be possibly higher vitamin D levels, which afford protection against several other viral and bacterial infections by $\mathrm{T}$ cell enhancement [18], although this hypothesis needs to be tested further. At high altitudes, there is lower air density and greater distance between molecules that might be responsible for smaller size of the airborne virus inoculum than at sea level [6].

\section{Conclusion}

Our data suggests a positive influential role of high altitude in decreasing the prevalence of SARSCoV2 infection, attributable to physiological adaptation as well as certain other favourable environmental factors including ultraviolet radiation, among high altitude inhabitants of India. Furthermore, erythropoietin can be explored as an adjuvant treatment in COVID-19 patients with hypoxemia, owing to its role in acclimatization at high altitude.
Contributors: SD was involved in planning the study, manuscript writing, data analysis and literate search. She will act as a study guarantor and approved the final version of this manuscript and is responsible for all aspects of this study.

Funding: None; Competing interests: None stated.

\section{References}

1. CDC COVID-19 Response Team, Chow N, FlemingDutra K, Gierke R, Hall A, Hughes M, Pilishvili T, Ritchey M, Roguski K. Preliminary estimates of the prevalence of selected underlying health conditions among patients with coronavirus disease 2019-United States, February 12-March 28, 2020. Morbidity and Mortality Weekly Report. 2020;69(13):382-386.

2. Eurosurveillance Editorial Team. Note from the editors: World Health Organization declares novel coronavirus (2019-nCoV) sixth public health emergency of international concern. Eurosurveillance. 2020;25(5):200131e.

3. Dong E, Du H, Gardner L. An interactive web-based dashboard to track COVID-19 in real time. The Lancet Infectious Diseases. 2020;20(5):533-534.

4. Delhi N. Ministry of Health and family welfare. Government of India. 2001:7-30. Available at: https:// www.mohfw.gov.in/ Accessed September 22, 2020.

5. Segovia-Juarez J, Castagnetto JM, Gonzales GF. High altitude reduces infection rate of COVID-19 but not casefatality rate. Respiratory Physiology \& Neurobiology. 2020; 281:103494.

6. Arias-Reyes C, Zubieta-DeUrioste N, Poma-Machicao L, Aliaga-Raudan F, Carvajal-Rodriguez F, Dutschmann $\mathrm{M}$, et al. Does the pathogenesis of SAR-CoV-2 virus decrease at high-altitude? Respiratory Physiology \& Neurobiology. 2020:103443.

7. Lu R, Zhao X, Li J, Niu P, Yang B, Wu H, et al. Genomic characterisation and epidemiology of 2019 novel coronavirus: implications for virus origins and receptor binding. The Lancet. 2020;395(10224):565-574.

8. Hamming I, Timens W, Bulthuis ML, Lely AT, Navis GV, van Goor H. Tissue distribution of ACE2 protein, the functional receptor for SARS coronavirus. A first step in understanding SARS pathogenesis. The Journal of Pathology: A Journal of the Pathological Society of Great Britain and Ireland. 2004;203(2):631-637.

9. Hampl V, Herget J, Bíbová J, Baňasová A, Husková $\mathrm{Z}$, Vaňourková Z, et al. Intrapulmonary activation of the angiotensin-converting enzyme type 2/angiotensin 1-7/G-protein-coupled Mas receptor axis attenuates pulmonary hypertension in Ren-2 transgenic rats exposed to chronic hypoxia. Physiol. Res. 2015;64(1):25-38.

10. Zhang R, Wu Y, Zhao M, Liu C, Zhou L, Shen S, et al. Role of HIF- $1 \alpha$ in the regulation ACE and ACE2 
expression in hypoxic human pulmonary artery smooth muscle cells. American Journal of Physiology-Lung Cellular and Molecular Physiology. 2009;297(4): L631640.

11. Kuba K, Imai Y, Rao S, Jiang C, Penninger JM. Lessons from SARS: control of acute lung failure by the SARS receptor ACE2. Journal of Molecular Medicine. 2006;84(10):814-820.

12. Dang Z, Su S, Jin G, Nan X, Ma L, Li Z, et al. Tsantan Sumtang attenuated chronic hypoxia-induced right ventricular structure remodeling and fibrosis by equilibrating local ACE-AngII-AT1R/ACE2-Ang1-7Mas axis in rat. Journal of Ethnopharmacology. 2020; 250:112470.

13. Chawla S, Saxena S. Physiology of high-altitude acclimatization. Resonance. 2014;19(6):538-548.

14. Martin D, Windsor J. From mountain to bedside: understanding the clinical relevance of human acclimatisation to high-altitude hypoxia. Postgraduate Medical Journal. 2008;84(998):622-627.
15. Tansey EA. Teaching the physiology of adaptation to hypoxic stress with the aid of a classic paper on high altitude by Houston and Riley. Advances in Physiology Education. 2008;32(1):11-17.

16. Soliz J, Schneider-Gasser EM, Arias-Reyes C, AliagaRaduan F, Poma-Machicao L, Zubieta-Calleja G, et al. Coping with hypoxemia: Could erythropoietin (EPO) be an adjuvant treatment of COVID-19? Respiratory Physiology \& Neurobiology. 2020:103476.

17. Andrade M. La radiación ultravioleta en tiempos de cuarentena. Pagina siete, Bolivia, Available at: https:// www. paginasiete. bo/opinion/2020/4/10/la-radiacionultravioleta-en-tiempos-decuarentena-252240. html. 2020. Accessed September 22, 2020.

18. Grant WB, Lahore H, McDonnell SL, Baggerly CA, French CB, Aliano JL, Bhattoa HP. Evidence that vitamin $\mathrm{D}$ supplementation could reduce risk of influenza and COVID-19 infections and deaths. Nutrients. 2020;12(4):988. 